\title{
Induced Unbalance as a Method for Improving the Dynamic Stability of High-Speed Turbochargers
}

\author{
R. Gordon Kirk ${ }^{1}$ and Ali A. Alsaeed ${ }^{2}$ \\ ${ }^{1}$ Department of Mechanical Engineering, Virginia Polytechnic Institute and State University, Blacksburg, VA 24060, USA \\ ${ }^{2}$ Department of Mechanical Engineering, King Fahd University of Petroleum and Minerals, Dhahran 31261, Saudi Arabia
}

Correspondence should be addressed to R. Gordon Kirk, gokirk@vt.edu

Received 13 September 2010; Accepted 5 January 2011

Academic Editor: Ningsheng Feng

Copyright ( 2011 R. Gordon Kirk and A. A. Alsaeed. This is an open access article distributed under the Creative Commons Attribution License, which permits unrestricted use, distribution, and reproduction in any medium, provided the original work is properly cited.

\begin{abstract}
The high-speed diesel engine turbocharger is known to have subsynchronous vibrations for a wide speed range. The bearing fluidfilm instability is the main source of the vibration. The nonlinear forces inside the bearings are causing the rotor to whirl in a limit cycle. This study presents a new method for improving the dynamic stability by inducing the turbocharger rotor unbalance in order to suppress the subsynchronous vibration. The finite-element model of the turbocharger with floating-ring bearings is numerically solved for the nonlinear time-transient response. Both compressor and turbine added unbalance are induced and the dynamic stability is computed. The turbocharger model with linearized floating-ring bearings is also solved for eigenvalues to predict the modes of instability. The linear analysis demonstrates that the forward whirling mode of the floating-ring at the compressor end also becomes unstable at the higher turbocharger speeds, in addition to the unstable forward conical and cylindrical modes. The numerical predictions are also compared to the former experimental results of a similar turbocharger. The results of the study show that the subsynchronous frequency amplitude of the dominant first mode is reduced when inducing either the compressor or the turbine unbalance at a certain level.
\end{abstract}

\section{Introduction}

The turbocharger industry is booming recently, and there is an urgent need for new evaluations of the overall design. As the oil prices continue to rise, along with the new emissions regulations strictly enforced for the in-road as well as the offroad vehicles, the transition to turbocharged engines, and especially for diesel engines, has become irresistible. Higher power, smaller engines, reduced emissions, and overall better efficiency are the main concerns. By means of the recent development in the computational tools, a new era of the product development has emerged.

Most diesel engine turbochargers incorporate floatingring bearings that use the engine's oil for lubrication. The high-speed turbocharger is known to have subsynchronous vibrations at high amplitudes for a wide speed range that could reach 150,000 rpm. The bearing fluid-film whirl instability is the main source of the subsynchronous vibration. The nonlinear reaction forces inside the bearings are usually causing the rotor to whirl in a limit cycle but may become large enough to cause permanent damages. Additionally, the lubrication oil may leak at higher rates through the seals into the engine or the exhaust emissions.

The objective of the current research is to investigate methods for improving the dynamic stability of the high-speed automotive turbochargers, especially designed for heavy-duty diesel engines that are used, for example, in heavy machinery, trucks, tractors, and so forth. The study utilizes the available modern computational tools in rotor dynamics in addition to the locally developed supportive computer codes. This research is a major part of the turbocharger dynamic analysis supporting the current extensive experimental tests in the Virginia Tech Rotor Dynamics Laboratory for the product development of different high-speed diesel engine turbochargers [1]. A common design assembly of the turbocharger consists of a radial outflow compressor and a radial inflow turbine on a single shaft. Bearings are mounted inboard, 


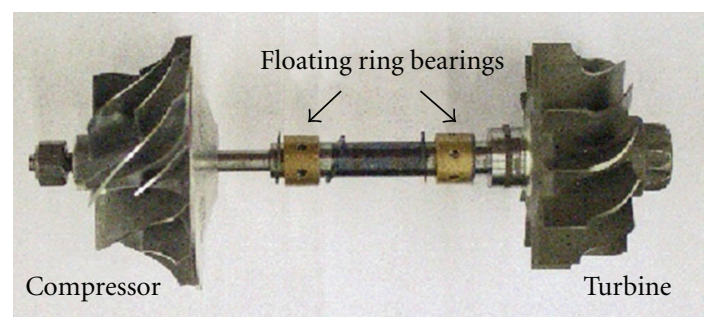

Figure 1: OEM Turbocharger.

with the compressor and turbine overhung, as shown in Figure 1.

This paper pioneers an alternative method in the suppression of high unstable vibrations of high-speed turbochargers. The new method is inducing the unbalance of the compressor and turbine wheels in order to suppress the instabilities. Several turbocharger finite-element models with various imbalance magnitudes on different locations are developed and numerically solved to obtain the nonlinear transient response in floating ring bearings. The dynamic coefficients of the floating ring bearings were also linearized and employed again in the turbocharger model to solve for eigenvalues and eigenvectors and hence the stability map of the rotor-bearing system. The numerical predictions are compared to the recent experimental results of a typical turbocharger with induced unbalance that was tested in the Virginia Tech Rotor Dynamics Laboratory [2].

Until recently, rotor-dynamic design of turbochargers has been mainly based on analysis of forced harmonic vibrations (Holmes et al. [3], $\mathrm{Li}$ and Rohde [4], and Shaw and Nussdorfer [5]). It was found that floating ring bearings were more resistant to self-excited vibration than plain journal bearings, and these became widely used. Even with floating ring bearings, many turbochargers show high levels of subsynchronous self-excited vibration (Alsaeed [6], Holmes et al. [3], and Tanaka et al. [7]). Figure 2 represents the waterfall frequency spectrum of a typical diesel engine turbocharger at full speed no load, showing high subsynchronous vibration amplitudes.

In recent years, development in computational methods have made the analysis of self-excited vibration easier, faster, and more reliable (Alsaeed [6], Gunter, Chen [8], and Kirk et al. [9]). Such analysis is becoming a fairly common part of the turbocharger rotor dynamic design process. Furthermore, there has been only limited experimental data for verification of modeling results (Kirk et al. [10-14]). Figure 3 displays the numerical predictions of a typical turbocharger rotor transient response at speed 100,000 rpm.

\section{Nonlinear Floating Ring Bearing}

Floating ring bearing has been widely used in turbocharger applications, where the rotor is light and runs at very high speed. Floating Ring Bearing can be treated as two fluid film (plain cylindrical) bearings in series. The inner film bearing has two rotating surface (shaft and bushing). The outer film bearing has only one rotating surface (bushing). Additional two degrees of freedom are introduced for each floating ring bearing due to its nonzero ring mass. Figure 4 shows the floating ring bearing and its model.

The radial clearances for the inner and outer films are

$$
\begin{aligned}
& C_{1}=\frac{D_{i}-D_{s}}{2}, \\
& C_{2}=\frac{D_{b}-D_{o}}{2},
\end{aligned}
$$

where $D_{s}$ is the shaft diameter, $D_{i}$ is the inner diameter of the ring, $D_{o}$ is the outer diameter of the ring, and $D_{b}$ is the bearing diameter. The journal rotates with an angular speed of $\Omega_{1}$ and the ring rotates with angular speed of $\Omega_{2}$.

It is a straightforward procedure for the nonlinear transient analysis by coupling the rotor equations with two Reynolds equations. Figure 5 represents the floating ring bearing data input in the finite element methods code [15] used in the analysis. The nonlinear fluid film forces for the inner and outer films are dependent on the motions of the journal and ring.

\section{Effects of Induced Imbalance on the Instabilities}

Early investigation by transient response analysis in the late 1960s [16] documented the level of imbalance required to produce a dominant synchronous vibration for a vertical rotor operating in plain journal bearings. That analysis of a vertical rotor revealed that an imbalance given by the following equation would prevent the large outward spiral of the nonlinear solution, by forcing the motion to be dominated by the synchronous vibration [2]

$$
\frac{e}{c}=0.16
$$

where $e=$ effective mass eccentricity, $c=$ radial bearing clearance.

For an effective mass of 33.75 grams $(0.03375 \mathrm{~kg})$, and a clearance of $0.02 \mathrm{~mm}$ ( 20 micron), the imbalance is

$$
U_{c}=33.75 \mathrm{~g} * 0.16 * 0.02 \mathrm{~mm}=0.108 \mathrm{~g}-\mathrm{mm} .
$$

This gives a starting value to begin the analytical investigation of the imbalance influence on the vibration amplitude due to the fluid-film bearing instability.

The unbalance was numerically simulated in the turbocharger FEM model as illustrated in Figure 6. One should notice that the OEM turbocharger is factory balanced, but normally, there is still small amount of unbalance that will be considered and simulated in the turbocharger model as "inherited unbalance". Starting with the compressor wheel in the turbocharger finite element model, imbalances are added with different amounts in order to compute for the rotor transient response. Nonlinear floating ring bearings (nonlinear dynamic coefficients) are employed in the turbocharger finite element model. The equation of motion of the rotorbearing system is numerically solved forward in time using the Wilson- $\theta$ integration method for constant operating 


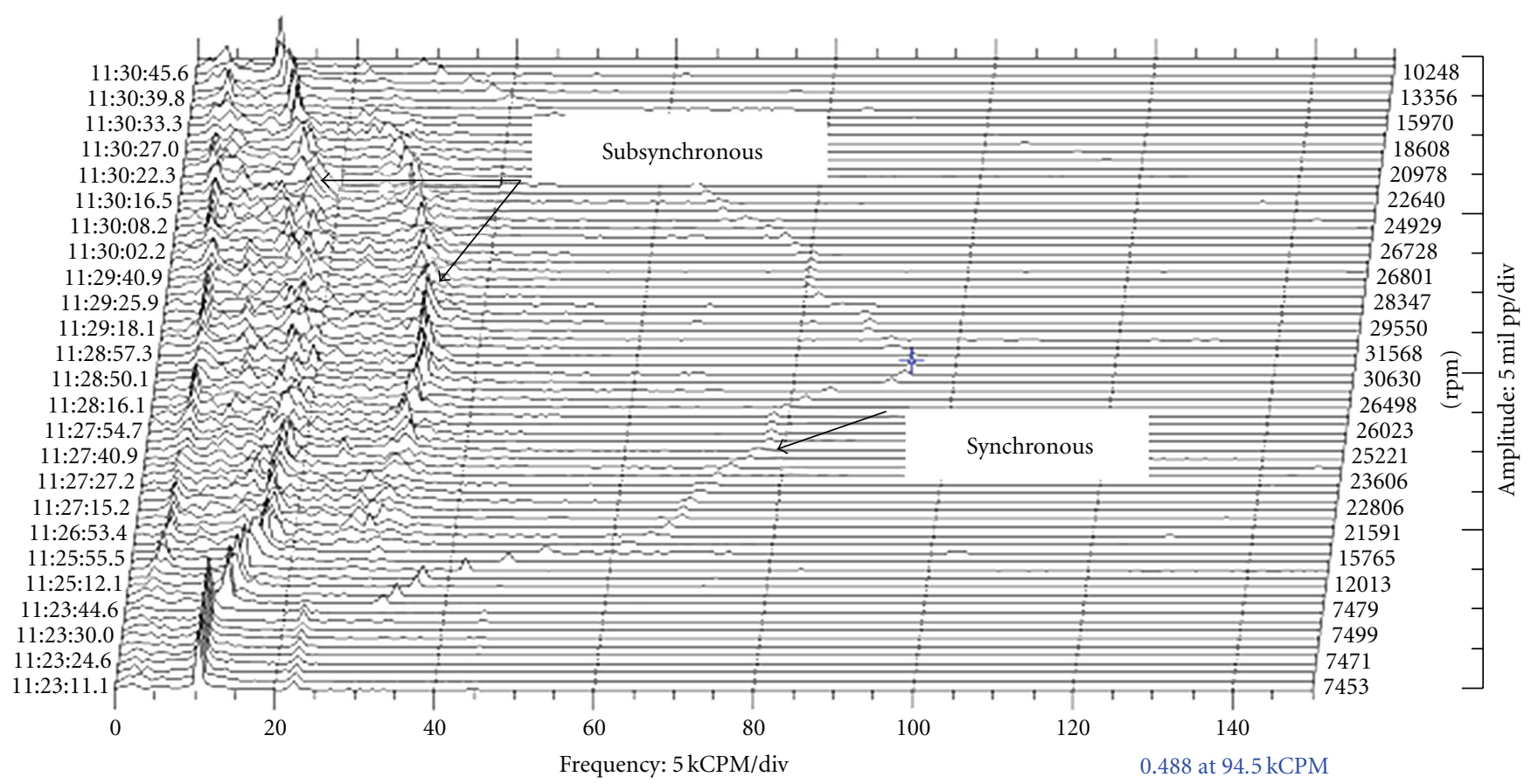

FIGURE 2: Waterfall frequency spectrum of a typical diesel engine turbocharger.

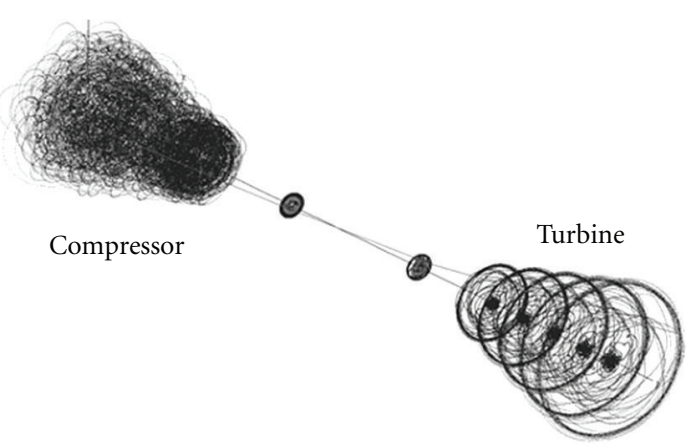

FIGURE 3: Numerical predictions of a typical turbocharger rotor transient response at speed 100,000 rpm [6].

speeds (steady-state) of 10, 20,30,.., $150 \mathrm{krpm}$. A small time step $\Delta t$ of $2 * 10^{-8}$ seconds for total 0.2 seconds, is used in the numerical integration for the solution convergence though it may be time consuming. The Fast Fourier Transform (FFT), which is a class of algorithms used in digital signal processing that break down complex signals into elementary components, is used to measure the numerically predicted subsynchronous vibration amplitudes.

Figure 7 represents the frequency spectrum for subject turbocharger model at the computed speeds. Subsynchronous vibrations persist at high amplitudes for much of the operating speed range. The first mode of instability builds up at $30 \mathrm{krpm}$ and continues at higher speeds. Another two modes of instability build up at lower speeds but have considerable amplitudes at speeds beyond $80 \mathrm{krpm}$. The synchronous vibrations on the other hand continue for the

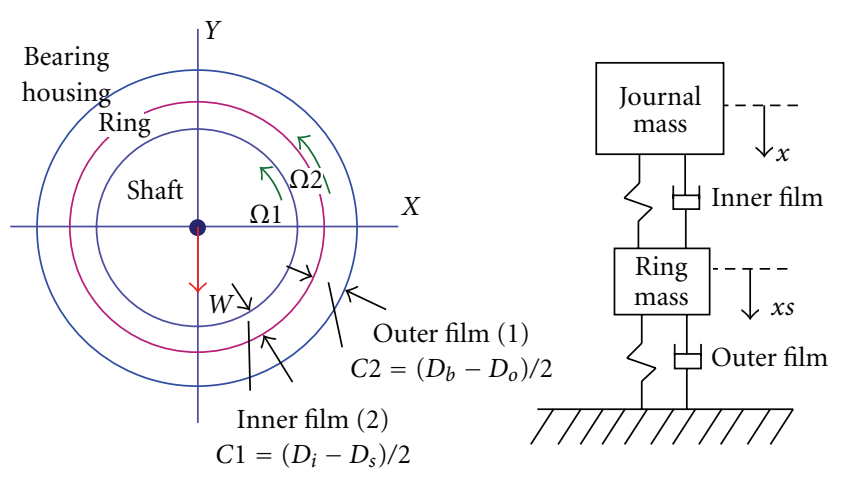

FIGURE 4: Floating ring bearing.

entire operating speed range with average amplitudes less than half of the largest subsynchronous amplitudes.

The floating ring bearings used in the above model in Figure 6, are now linearized about the static equilibrium position, and Reynolds equations are numerically solved for linear stiffness and damping coefficients. The floating ring bearings are considered as two bearings in series, and two equations for each bearing are solved. The new coefficients (inner and outer fluid-film dynamic coefficients for each bearing) are employed in the rotor model of Figure 6 in order to solve for eigenvalues and eigenvectors, and hence the stability characteristics of the system.

Figure 8 display the stability map of the turbocharger rotor in linearized floating ring bearings. At low speeds, there is one mode of instability. At midrange speeds, there are two modes of instability. At higher speeds, three modes of 

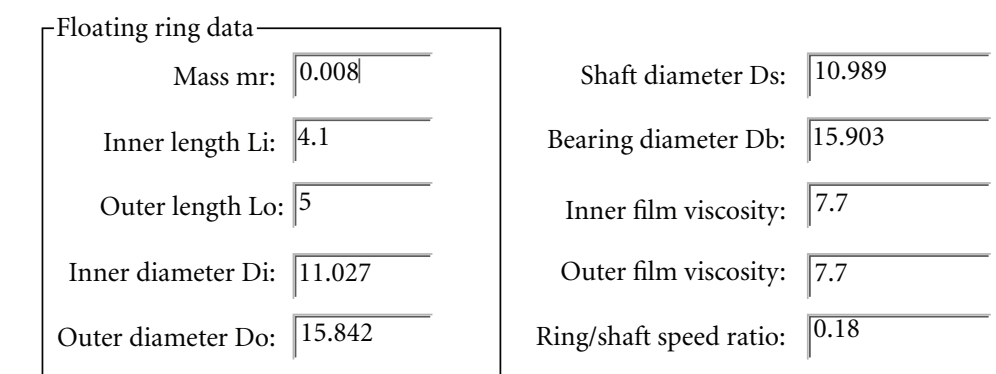

$C i=0.019 . \mathrm{Co}: 0.030 . \mathrm{Co} / \mathrm{Ci}=1.60526 . \mathrm{max}$. estimated speed ratio: 0.305239 . note: 0 for damper

Unit:(4)-geometry: mm. viscosity: centiPoise. M: kg

Figure 5: Floating ring bearing data input at compressor end.

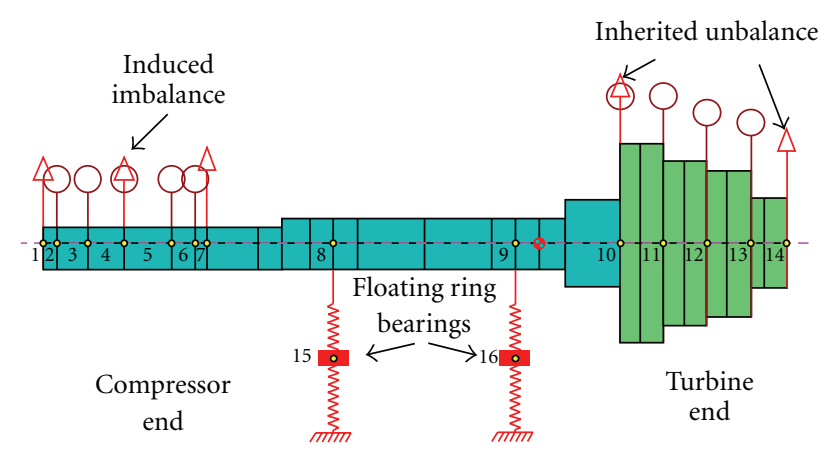

FIGURE 6: Turbocharger finite-element model with induced imbalance at the compressor wheel.

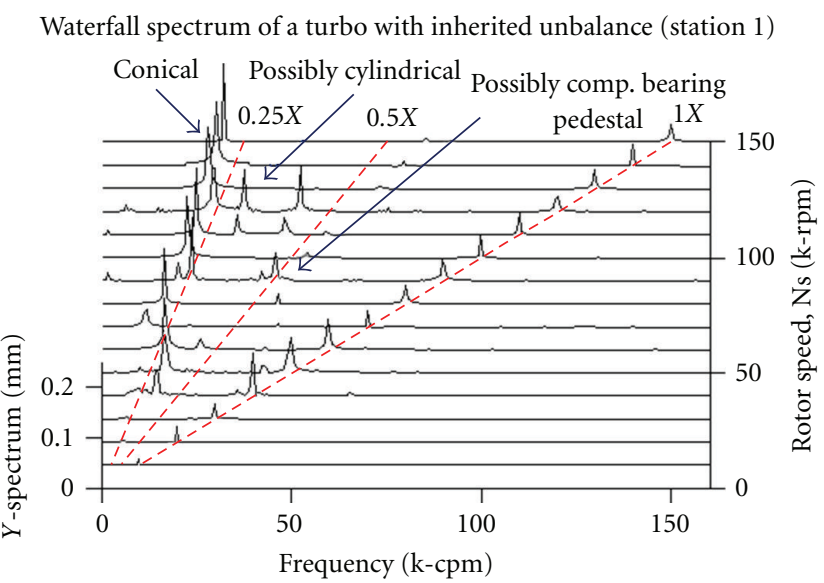

FIGURE 7: Frequency spectrum (waterfall) of a turbocharger with inherited unbalance in nonlinear floating ring bearings, computed at the compressor end tip (station 1).

instability persist simultaneously. Figure 9 shows the three modes of instability with the corresponding damped natural frequency (whirling speed), where at speed $50 \mathrm{krpm}$, the forward cylindrical mode is unstable. At speed $100 \mathrm{krpm}$, the forward conical mode is unstable in addition to the

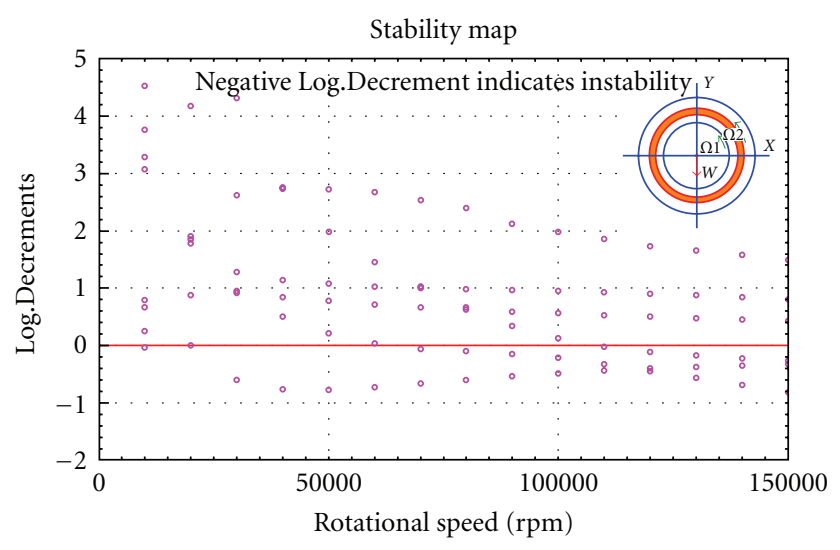

FIGURE 8: Stability map of turbocharger on two linearized floating ring bearings. (operating speeds, $N s=10,20, \ldots 150 \mathrm{krpm}$ ).

compressor pedestal resonance. At speed $150 \mathrm{krpm}$, there is a third mode of instability with a damped natural frequency in between the forward conical and compressor pedestal damped natural frequencies. The shape of the third mode of instability is much similar to the forward cylindrical mode.

The linear analysis may be useful now to interpret the results in Figure 7. First, in the linear analysis, there are three modes of instability that are predicted to become a source of subsynchronous vibration in the above nonlinear turbocharger model. Second, one should expect that the lowest frequency subsynchronous vibration is the forward conical mode, as shown in Figure 9. Also, the compressor pedestal tuning frequency is always the highest, in comparison to the other two modes of instability. Looking again at Figure 7, at speed $120 \mathrm{krpm}$, the lowest frequency subsynchronous vibration could be the forward conical mode, the higherfrequency subsynchronous vibration could be the forward cylindrical mode, and the highest subsynchronous vibration could be the compressor pedestal mode.

The objective now is to predict the turbocharger nonlinear transient response by inducing imbalance on either the compressor or turbine wheel. At speeds 50, 100, and 


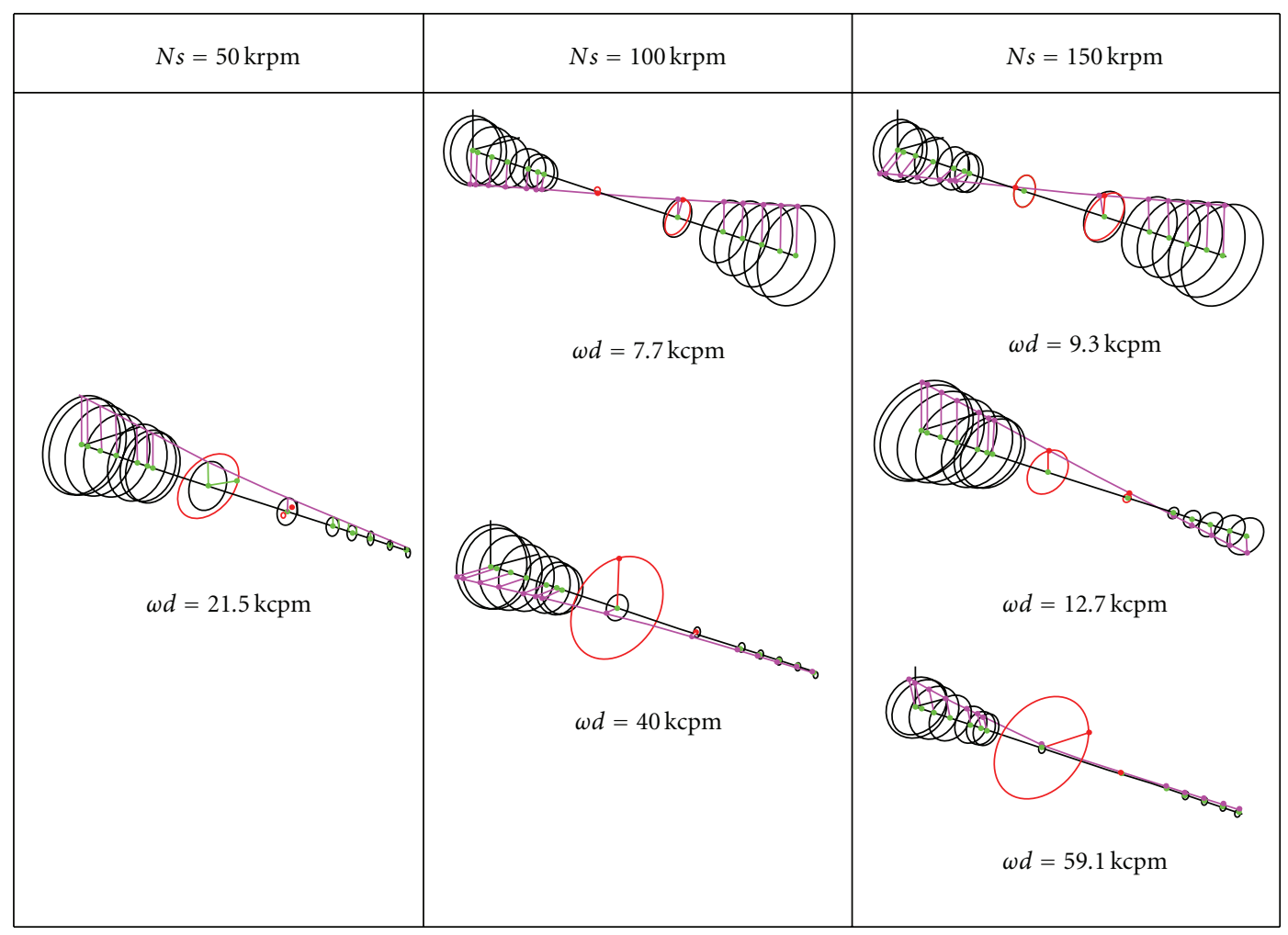

FIGURE 9: Predicted modes of instability for a turbocharger in two linearized floating ring bearings.

$150 \mathrm{krpm}$ (i.e., low, mid, and high speed), the system equations of motion are solved for transient response, and the FFT spectrum is computed. Three significant vibration signatures are investigated: the lower-frequency subsynchronous (Sub Low), the higher-frequency subsynchronous (Sub High), and the synchronous (1X).

Figure 10 represents a sample of the numerical predictions for the influence of induced compressor unbalance on the lower subsynchronous, higher subsynchronous, and the synchronous vibration amplitudes computed at the compressor end (station 1). In most of the computations, the dominant subsynchronous frequency is at the lowerfrequency (Sub Low), which is likely the forward conical mode. As the compressor imbalance is induced, the lowerfrequency subsynchronous amplitude decreases gradually to a certain limit, and then increases to an amplitude similar to the zero induced unbalance case, after which the amplitudes changes in irregular order. The higher-frequency subsynchronous vibration (Sub High), which could be either the forward cylindrical mode or the forward compressor pedestal mode, can only be seen at the higher speeds 100 and $150 \mathrm{krpm}$. Those Sub High amplitudes are relatively low when using very low induced imbalance, but in some cases when using much higher induced unbalance, the Sub High amplitudes become significant. Also, the predicted Sub High amplitudes are relatively much higher at the compressor end and the compressor bearing (see Figure 10), and that might be trivial since the forward cylindrical mode displays higher amplitude at the compressor end than the turbine end.
The synchronous vibration amplitude changes slightly as the induced unbalance increases, but becomes significantly very high at the larger imbalance especially on the compressor end and compressor bearing stations. The largest synchronous vibration amplitudes were computed at the lower speed $50 \mathrm{krpm}$, with highest induced unbalance, where it becomes more than 0.25 mm-pk. (See Figure 10(a).)

The average vibrations amplitudes are calculated at running speeds 50,100 , and $150 \mathrm{krpm}$ in order to investigate the effect of induced imbalance on the instability levels at typical operating conditions (i.e., low, mid, and high speeds). The objective is to study whether there is indeed an optimum imbalance that will at least reduce the subsynchronous vibrations amplitudes.

Figure 11 represents a sample of the predicted average vibrations amplitudes at the compressor end tip (station 1), when inducing the compressor unbalance, $U c$. The average Sub Low, Sub High, and $1 X$ are plotted in those figures to predict the optimum induced compressor unbalance that can be used to suppress the unstable vibrations. Since the Sub Low amplitudes are dominant for the lower induced compressor unbalance, the first optimum $U c$ that would give the lowest Sub Low amplitudes at the four stations (stations $1,8,9$, and 14$)$ is $0.108 \mathrm{~g}-\mathrm{mm}(e / c=0.16)$. The Sub Low amplitudes are reduced by $15 \%-16 \%$ at the four stations. Also, another optimum response is predicted when using the induced compressor unbalance $U_{c}$ of $0.864 \mathrm{~g}-\mathrm{mm}$ $(e / c=1.28)$. The Sub Low amplitudes are reduced to $26-48 \%$ at the four rotor stations. The Sub High amplitudes are still 


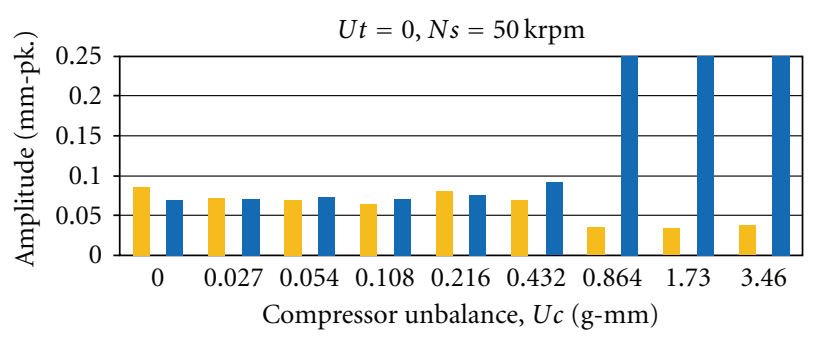

(a)

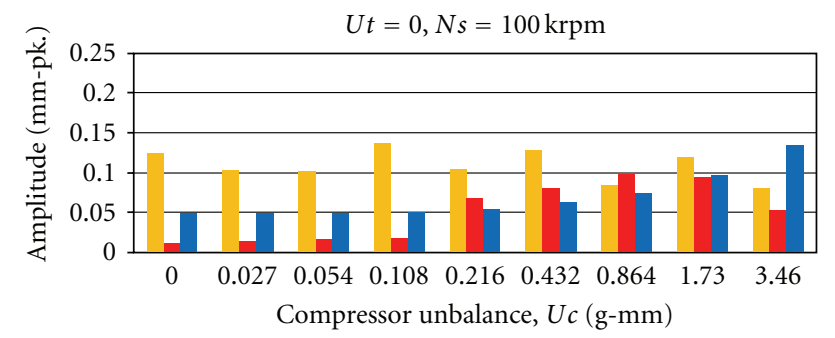

(b)

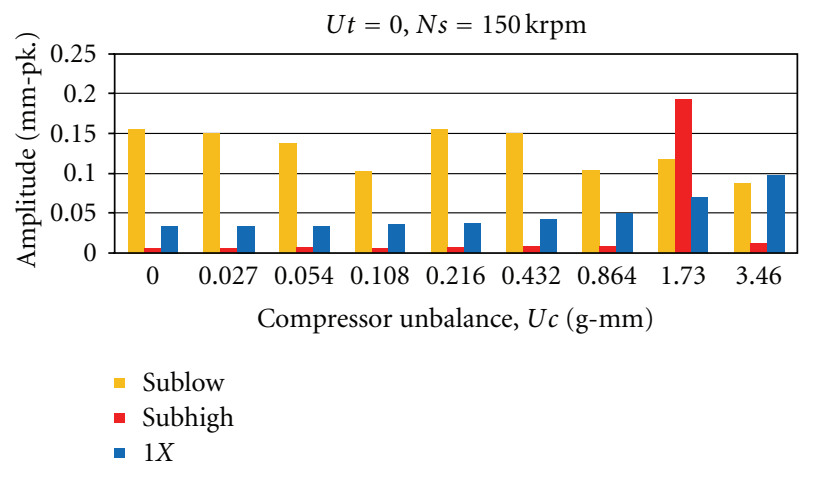

(c)

Figure 10: Predicted compressor end (Station 1) vibration for induced compressor unbalance at (a) $50 \mathrm{krpm}$, (b) $100 \mathrm{krpm}$, and (c) $150 \mathrm{krpm}$.

below $0.05 \mathrm{~mm}-\mathrm{pk}$. at the compressor and turbine stations, and below $0.01 \mathrm{~mm}-\mathrm{pk}$. at the compressor bearing and the turbine bearing stations. The predicted synchronous $1 X$ amplitudes did not change much at most stations, but it is relatively high at the compressor end station with $0.155 \mathrm{~mm}-\mathrm{pk}$.

Table 1 shows the compressor and turbine bearings clearances used in the analysis. Those clearances are recommended by the turbocharger manufactures for analysis. The OEM turbocharger service data sheet recommends the Total Indicator Reading (TIR) for the radial movement of the compressor end tip to be $0.330-0.508 \mathrm{~mm}$.

Figure 12 represents a sample of the predicted average vibrations amplitudes at the compressor end tip (station 1), when inducing the turbine unbalance, Ut. This time, the average Sub Low, Sub High, and $1 X$ are plotted in those figures to predict the optimum induced turbine unbalance that can be used to suppress the unstable vibrations. Also, Since the Sub Low amplitudes are dominant for the lower induced compressor unbalance, the first optimum $U t$ that
TABLE 1: Compressor and turbine bearings clearances.

\begin{tabular}{lccc}
\hline & $\begin{array}{c}\text { Inner clearance, } \\
\text { Ci }(\mathrm{mm})\end{array}$ & $\begin{array}{c}\text { Outer clearance, } \\
\text { Co }(\mathrm{mm})\end{array}$ & $\begin{array}{c}\text { Total clearance, } \\
\mathrm{Ci}+\mathrm{Co}(\mathrm{mm})\end{array}$ \\
\hline $\begin{array}{l}\text { Compressor } \\
\text { end bearing }\end{array}$ & 0.0190 & 0.0305 & 0.0495 \\
$\begin{array}{l}\text { Turbine end } \\
\text { bearing }\end{array}$ & 0.0205 & 0.0270 & 0.0475 \\
\hline
\end{tabular}

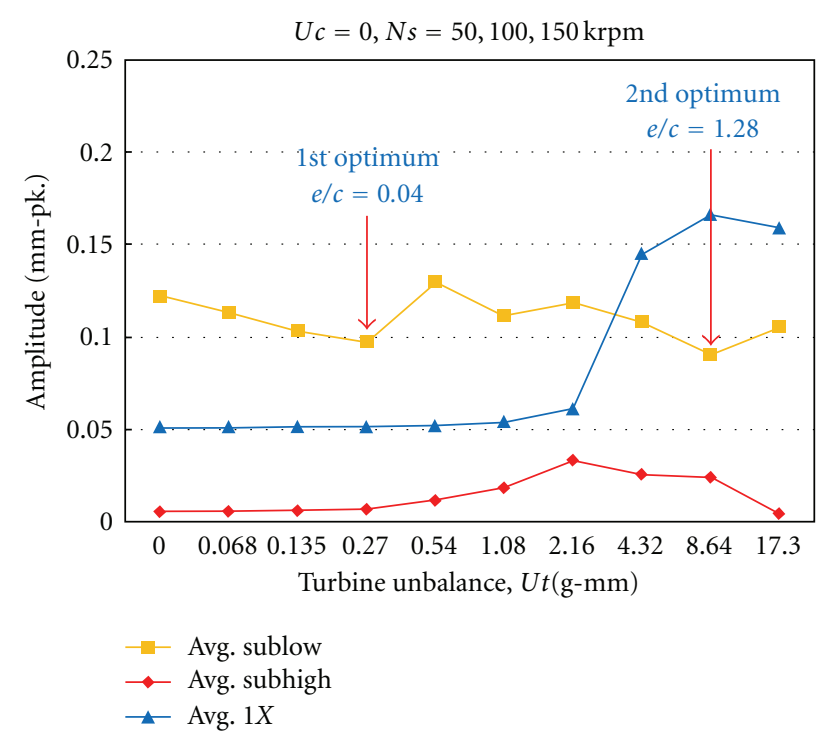

FIGURE 11: Predicted average compressor end (Station 1) vibration for induced compressor unbalance at speeds 50, 100, and $150 \mathrm{krpm}$.

would give the lowest Sub Low amplitudes at the four stations (stations $1,8,9$, and 14$)$ is $0.27 \mathrm{~g}-\mathrm{mm}(e / c=0.04)$. The Sub Low amplitudes are reduced by 18\%-20\% at the four turbocharger rotor stations. Similar to the preceding results, another optimum response is predicted when using the induced compressor unbalance $U t$ of $8.64 \mathrm{~g}-\mathrm{mm}(e / c=1.28)$. The Sub Low amplitudes are reduced by $16 \%-34 \%$ at the rotor stations 1, 8, and 9. However, the Sub Low is only reduced by $6 \%$ at the station 14 (turbine end). Also, the Sub High amplitudes are kept below $0.05 \mathrm{~mm}-\mathrm{pk}$. at the compressor and turbine stations, and below $0.01 \mathrm{~mm}-\mathrm{pk}$. at the compressor bearing and the turbine bearing stations. The predicted synchronous $1 X$ amplitudes are below $0.02 \mathrm{~mm}$ pk. at both bearings stations, and about $0.059 \mathrm{~mm}-\mathrm{pk}$. at the turbine end station. The computed $1 X$ at the compressor end station is relatively high with $0.166 \mathrm{~mm}$-pk.

As mentioned earlier, the total clearance at the compressor bearing is $0.0495 \mathrm{~mm}$, and at the turbine bearing is $0.0475 \mathrm{~mm}$. Also, the Total Indicator Reading (TIR) for the radial movement of the compressor end tip is $0.330-0.508 \mathrm{~mm}$, as recommended by the turbocharger manufacturer. 


\section{Experimental Results of a Typical Turbocharger}

The turbocharger used for the former experimental research by Kirk et al. [2] is a mid-size design that was matched for use with a 3.9 Liter diesel test engine. The assembly of the turbocharger charger is similar to the current design used in the analysis but with a relatively larger geometry. The major goal of the experimental tests was to document the influence that the added imbalance has on the levels of subsynchronous vibration.

Setscrews were used to produce imbalance equal to 1.46 g-mm, just slightly less than the value computed for a $1 \mathrm{lb}(453.6 \mathrm{~g})$ effective mass. Several imbalance levels are planned, but currently results are available only for the balanced condition $(0.15 \mathrm{~g}-\mathrm{mm})$, and imbalance levels of 1.46 and $0.0906 \mathrm{~g}-\mathrm{mm}$. The influence on the 1 st mode, lowerfrequency instability is shown below in Figure 13 for runs 11-15. It is clear that the subsynchronous levels are lower for the unbalanced rotor.

The imbalance runs were noted as Run 11 for 1.46 g-mm, and Runs 13, 14, and 15 were for $0.9 \mathrm{~g}-\mathrm{mm}$. The spectrum content for Run 14 with $0.906 \mathrm{~g}-\mathrm{mm}$ imbalance is presented in Figure 14, where the synchronous vibration has increased to 2.83 mil-pp $(0.072 \mathrm{~mm}$-pp $\approx 0.036 \mathrm{~mm}$-pk.), compared to 1.31 mil-pp $(0.033 \mathrm{~mm}$-pp $\approx 0.017 \mathrm{~mm}$-pk. $)$ at the maximum speed for the residual imbalance condition of Run 12.

The influence on the second-mode instability is shown in Figure 15, where the effect is not as clear as for the lower mode. These results indicate that the compressor end imbalance can be effective to control the first mode instability. It is clear that the second mode is not controlled by the compressor end imbalance. Additional runs will be made for the turbine end imbalance to examine the influence on both first and second mode of instability vibration levels.

The experimental results of the typical turbocharger with relatively larger geometry agree with the numerical predictions of Figure 11, especially for the higher induced compressor imbalance. The predicted average $1 X$ amplitudes are almost doubled for the induced compressor imbalance higher than $0.432 \mathrm{~g}-\mathrm{mm}$, which can also be seen in the experimental results (see Figure 13). The predicted average Sub Low amplitudes are reduced by more than 30\% for the induced compressor imbalance more than $0.432 \mathrm{~g}-\mathrm{mm}$, and that is also similar to the experimental results. The predicted average Sub High amplitudes are significantly increased for the higher induced compressor imbalance, which also agrees with the above experimental results. It should be noted that although the computed Sub High builds up at the higher speeds, the Sub High amplitudes in Figure 11 are the average at speeds 50, 100, and $150 \mathrm{krpm}$. Therefore, Sub High in Figure 11 should be multiplied by a factor of 1.5 to get an average value that corresponds to the experimental Sub High of Figure 15. As a result, the predictions of the Sub High amplitudes become comparable to the experimental results as the induced compressor imbalance are increased.

There could be several factors influencing the Sub High in the experimental results that are not considered in the above numerical predictions. Some of the factors could be the

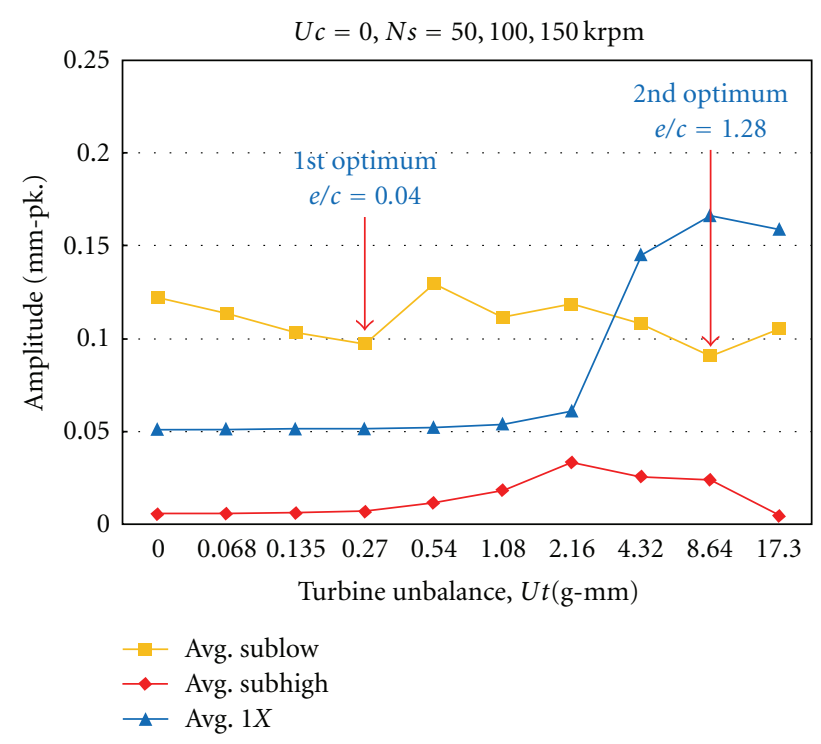

FIGURE 12: Predicted average compressor end (Station 1) vibration for induced turbine unbalance at speeds 50, 100, and $150 \mathrm{krpm}$.

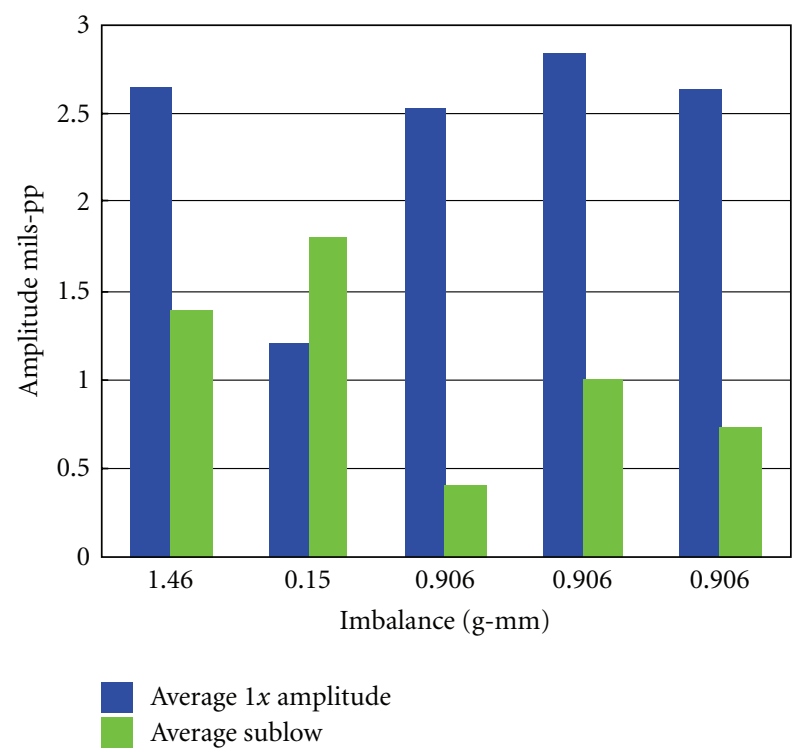

FIgURe 13: Average levels for runs 11-15, sync, and 1st mode [2].

radial aerodynamic force developed in either the compressor or the turbine volute as a result of loading the engine and hence pressure variation. Another factor could be the engineinduced vibration of the turbocharger casing, which might also affect our analysis. These two effects will be studied in another publication.

The experimental testing is in progress at the Virginia Tech Rotor Dynamics Laboratory. The new results will be hopefully published in the future.

\section{Conclusions}

This paper pioneered an alternative method in the suppression of high unstable vibrations of high speed turbochargers. 


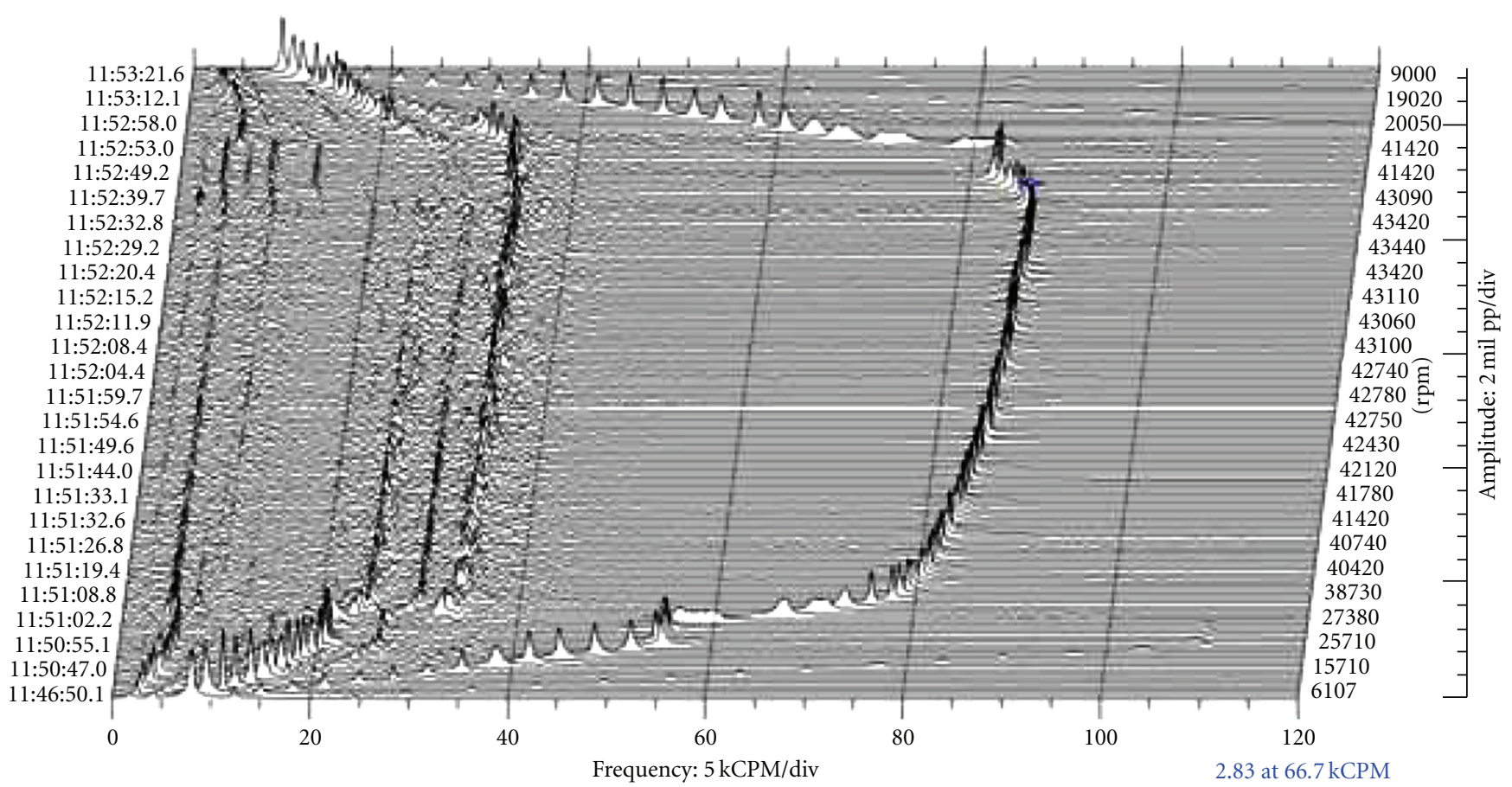

FIGURE 14: Compressor vertical probe frequency content Residual imbalance Run 14, 86, 700 rpm max speed [2].

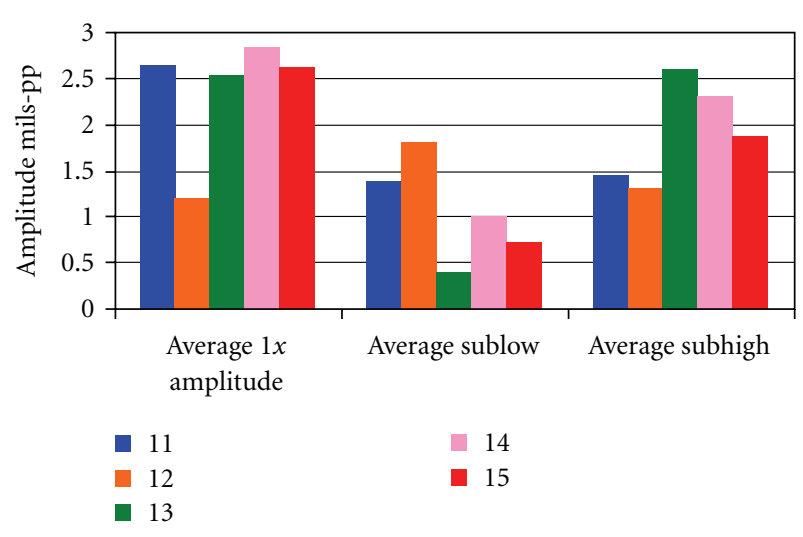

Figure 15: Average levels for Runs 11-15, sync, 1st, and 2nd mode [2].

The new method is inducing the unbalance of the compressor or the turbine wheels in order to suppress the instabilities. The basic concept of modeling the nonlinear floating ring bearing was presented. Several turbocharger finite element models with various imbalance loads on different locations were developed and numerically solved in order to investigate the effects on the subsynchronous and synchronous vibration amplitudes and a sample of the predictions was presented. Additionally, a turbocharger model with linearized floating ring bearings was solved for eigenvalues and eigenvectors to study the modes of instability. Finally, the experimental test results of a typical turbocharger with induced unbalance are compared to the current numerical predictions. The summary of the main results is the following.

(1) The method of induced unbalance was successful in reducing the amplitudes of the first mode of instability (Sub Low).

(2) When inducing the compressor unbalance, the Sub Low was reduced by up to $16 \%$ with $e / c=0.16$ and by up to $48 \%$ with $e / c=1.28$.

(3) Also, when inducing the turbine unbalance, the Sub Low was reduced by up to $20 \%$ with $e / c=0.04$ and by up to $34 \%$ with $e / c=1.28$.

(4) For the induced compressor unbalance at $e / c \geq 1.28$, the Sub High was increased to be at comparable amplitudes with the Sub Low, but the synchronous frequency $(1 X)$ was dominant. The results also agree with the experimental results of a typical turbocharger.

(5) For the induced turbine unbalance at $e / c \geq 0.64$, the Sub High amplitudes were reduced and remained much below the Sub Low amplitudes, and the synchronous frequency $1 X$ was dominant.

(6) Although it is time consuming, nonlinear transient analysis is recommended to examine the performance of the complex rotor-bearing system.

The experimental testing is in progress at the Virginia Tech Rotor Dynamics Laboratory to investigate the influence of inducing the turbine unbalance on subsynchronous vibrations. The new results will be hopefully published in the future. 


\section{Nomenclature}

1X: $\quad$ Synchronous vibration

Sub High: Higher-frequency subsynchronous vibration

Sub Low: Lower-frequency subsynchronous vibration

$U_{t}: \quad$ Induced turbine unbalance (g-mm)

$U_{c}: \quad$ Induced compressor unbalance ( $\left.\mathrm{g}-\mathrm{mm}\right)$

$\Omega: \quad$ Shaft rotational speed $(\mathrm{rad} / \mathrm{sec})$.

\section{Acknowledgments}

The authors would like to acknowledge the generous financial support from King Fahd University of Petroleum and Minerals and King Abdullah University of Science and Technology to conduct this research.

\section{References}

[1] A. A. Alsaeed, A study of methods for improving the dynamic stability of high-speed turbochargers, Ph.D. dissertation, Virginia Polytechnic Institute and State University, Blacksburg, Va, USA, 2010.

[2] R. G. Kirk, J. Sterling, W. Sawyers, M. Seville, T. B. McNiff, and L. Wilvert, "Influence of turbocharger imbalance on subsynchronous vibration amplitude," in Proceedings of the ASME/STLE International Joint Tribology Conference (IJTC '09), pp. 213-215, Memphis, Tenn, USA, October 2009.

[3] R. Holmes, M. J. Brennan, and B. Gottrand, "Vibration of an automotive turbocharger-a case study," in Proceedings of the 8th International Conference on Vibrations in Rotating Machinery, IMechE Conference Transactions, pp. 445-450, September 2004.

[4] C. H. Li and S. M. Rohde, "On the steady state and dynamic performance characteristics of floating ring bearings," ASME Transactions Journal of Lubrication Technology, vol. 103, no. 3, pp. 389-397, 1981.

[5] M. C. Shaw and T. J. Nussdorfer, "An analysis of the fullfloating journal bearing," Tech. Rep. 866, NACA, 1947.

[6] A. A. Alsaeed, Dynamic stability evaluation of an automotive turbocharger rotor-bearing system, M.S. thesis, Virginia Polytechnic Institute and State University, Blacksburg, Va, USA, 2005.

[7] M. Tanaka, K. Hatakenaka, and K. Suzuki, "A theoretical analysis of floating bush journal bearing with axial oil film rupture being considered," ASME Transactions Journal of Tribology, vol. 124, no. 3, pp. 494-505, 2002.

[8] E. J. Gunter and W. J. Chen, "Dynamic analysis of a turbocharger in floating bushing bearings," in Proceedings of the 3rd International Symposium on Stability Control of Rotating Machinery (ISCORMA '08), Cleveland, Ohio, USA, September 2005.

[9] R. G. Kirk, A. A. Alsaeed, and E. J. Gunter, "Stability analysis of a high speed automotive turbocharger," Tribology Transactions, vol. 50, no. 3, pp. 427-434, 2007.

[10] R. G. Kirk, A. A. Kornhauser, J. Sterling, and A. Alsaeed, "Turbocharger on-engine experimental vibration testing," Journal of Vibration and Control, vol. 16, no. 3, pp. 343-355, 2010.

[11] R. G. Kirk, A. A. Alsaeed, J. Liptrap et al., "Experimental test results for vibration of a high speed diesel engine turbocharger," Tribology Transactions, vol. 51, no. 4, pp. 422427, 2008.
[12] R. G. Kirk, J. Sterling, R. Utara et al., "Diesel engine turbocharger rebuild and experimental testing," in Proceedings of the ASME/STLE International Joint Tribology Conference (IJTC '07), pp. 485-487, San Diego, Calif, USA, October 2007.

[13] R. G. Kirk, A. Kornhauser, J. Sterling, and A. Alsaeed, "High speed turbocharger instability," in Proceedings of the 4th International Symposium on Stability Control of Rotating Machinery (ISCORMA '07), Calgary, Canada, August 2007.

[14] R. G. Kirk and J. C. Nicholas, "Experimental study of high speed turbocharger dynamic stability," in Proceedings of the 9th International Conference on Vibrations in Rotating Machinery, vol. 2 of IMechE Conference Transactions, pp. 685-696, Exeter, UK, September 2008.

[15] W. J. Chen and E. J. Gunter, Introduction to Dynamics of RotorBearing Systems, Trafford, Victoria, Canada, 2005.

[16] R. G. Kirk and E. J. Gunter, "Transient journal bearing analysis," Tech. Rep. NASA CR-1549, NASA, Washington, DC, USA, 1970. 

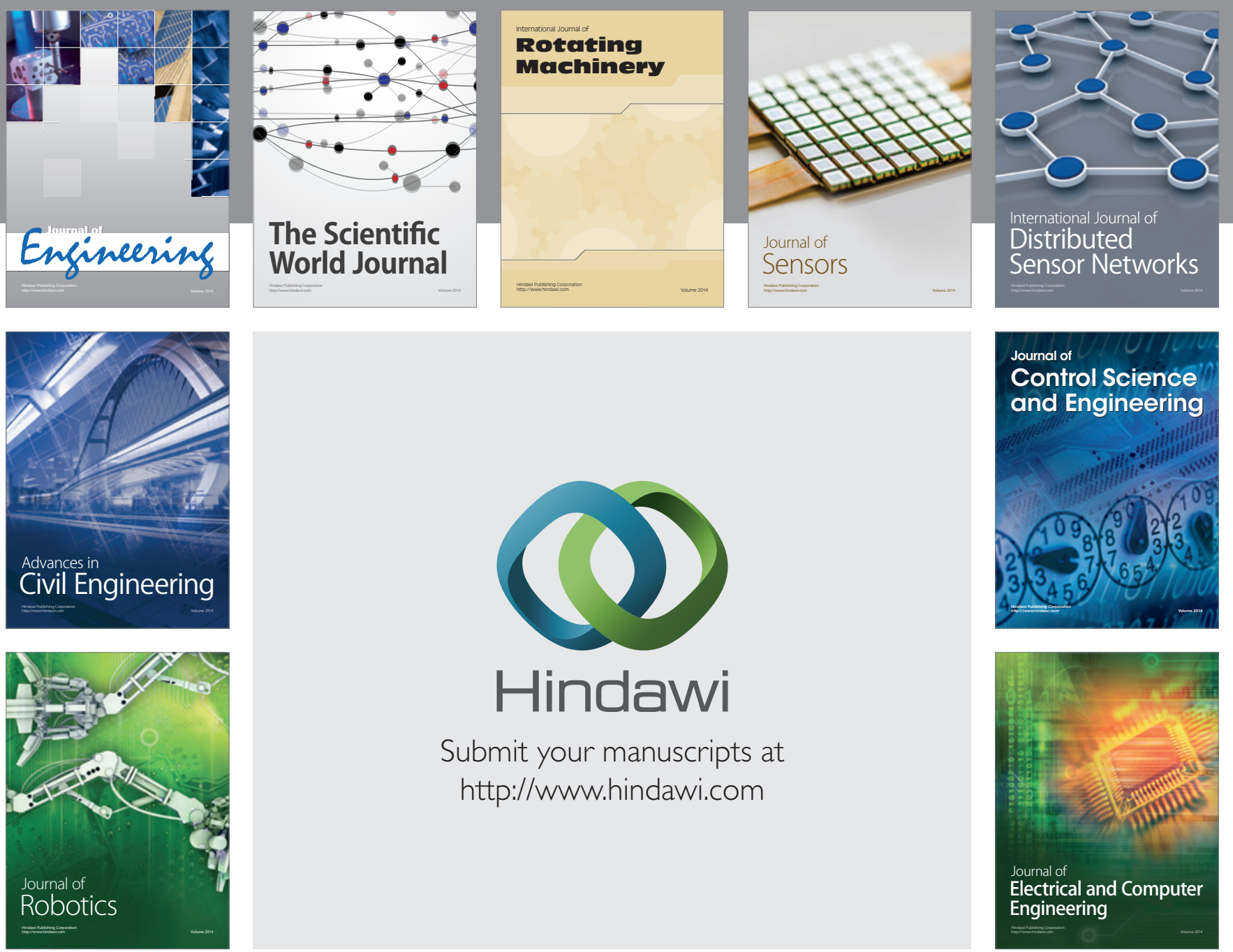

Submit your manuscripts at

http://www.hindawi.com
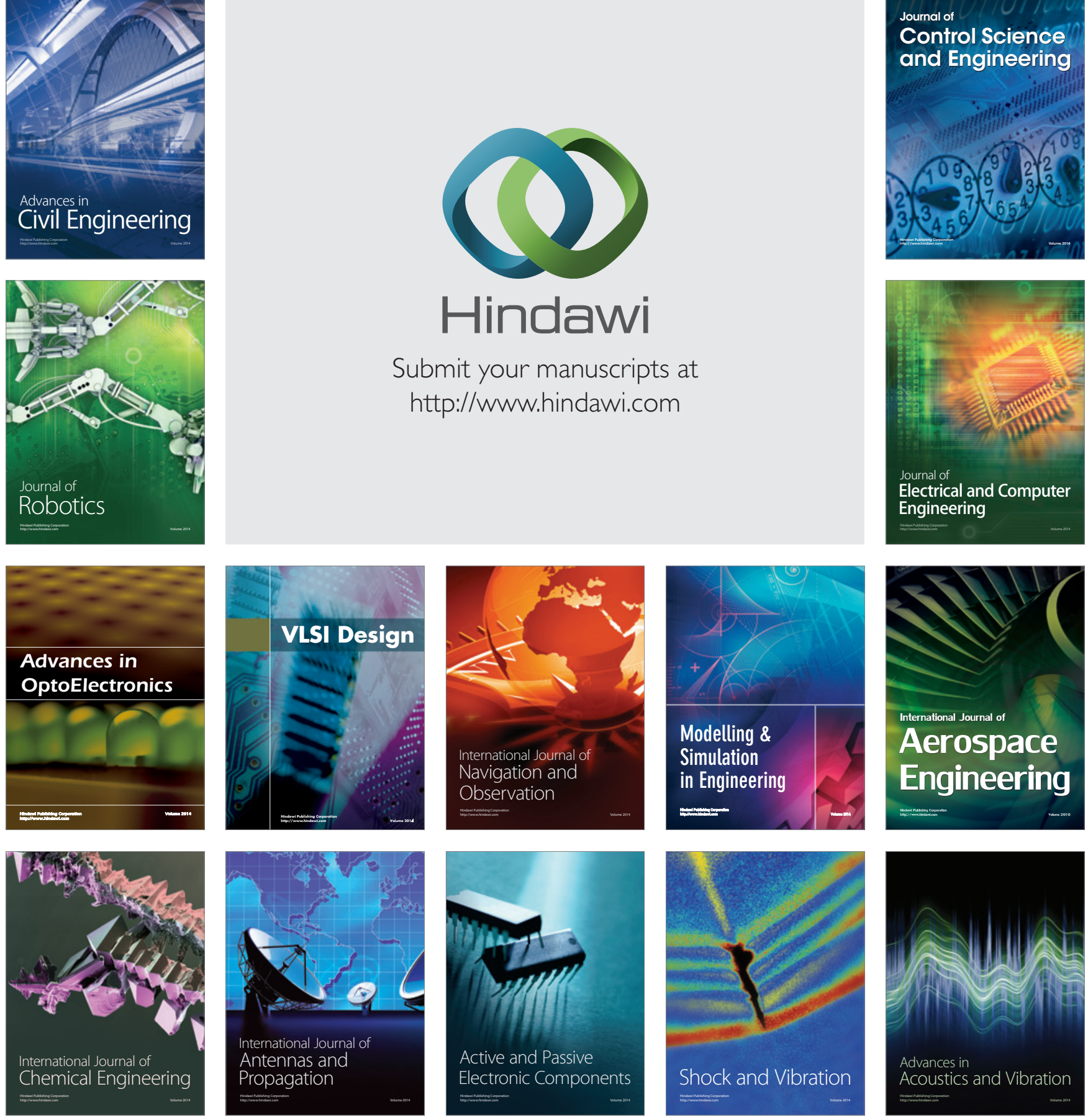